\title{
Ensaio
}

\section{Pierre Bourdieu: um diálogo entre seus conceitos básicos e os estudos de gênero}

\author{
Laís Emanuelle Borba de Brito' \\ Josenildo Soares Bezerra²
}

\section{Resumo}

O seguinte artigo tem o intuito de apresentar e abordar os principais conceitos do teórico Pierre Bourdieu por meio da exposição de suas bases sociológicas e antropológicas e aproximações com os estudos de gênero.

Palavras-chave: mídia; Pierre Bourdieu, produção de sentidos.

\begin{abstract}
The following expanded summary aims to present and address the main concepts of the theorist Pierre Bourdieu through an exposition of his sociological and anthropological premises and approaches to gender studies.

Keywords: media; Pierre Bourdieu; meaning production.
\end{abstract}

\section{Introdução}

Considerado um dos maiores nomes da sociologia das últimas décadas, Pierre Bourdieu é um dos importantes teóricos do século XX. Sua obra é referência na antropologia e na sociologia, trabalhando com variados temas, como a educação, comunicação, política, cultura, artes, literatura, linguística, etc.

Suas obras podem ser compreendidas como abarcando uma teoria de estruturas sociais por meio de alguns conceitos-chaves: campo, habitus, capital, violência simbólica, poder simbólico. Diante de suas investigações, ele vai definir uma variante do que seria o

\footnotetext{
' Mestranda no Programa de Pós Graduação em Estudos da Mídia (PPGEM) pela Universidade Federal do Rio Grande do Norte (UFRN). laisemanuelle_2012@hotmail.com

2 Doutor em Estudos da Linguagem pela Universidade Federal do Rio Grande do Norte (UFRN) e professor no curso de Publicidade e Propaganda da Universidade Federal do Rio Grande do Norte (UFRN). soares.bezerra@gmail.com
} 


\section{VOZES $_{\text {\&IÁLORO }}^{\mid}$}

Itajaí, V. 20, n.01, jan-jun 2021

estruturalismo. Assim sendo, busca traçar uma problemática que coloque em evidência a presença de estruturas que se encontram implícitas na sociedade.

Esse estruturalismo, para Bourdieu, abre espaço à uma função crítica das articulações que são envolvidas pelo social. $\mathrm{O}$ autor vai buscar compreender quais são, por exemplo, os mecanismos de dominação, como eles produzem ideais e em que ponto influenciam nos comportamentos dos agentes.

O seguinte trabalho tem como objetivo apresentar o autor e suas bases, além de compreender seus conceitos. Parte de uma apresentação de conceitos-chaves para o autor que seriam: campo, habitus, capital, violência simbólica, poder simbólico. Desse modo, busca uma discussão sobre sua teoria, remetendo suas contribuições a questões de gênero. Inicialmente, o texto apresenta a trajetória do autor, em seguida, são apresentados seus conceitos principais e suas considerações a respeito de questões de gênero.

\section{Pierre Bourdieu}

Pierre Félix Bourdieu nasceu em $1^{\circ}$ de agosto de 1930, em Denguin, uma pequena cidade localizada na região do Béarn, no sudoeste da França. Nascido em uma família humilde, seu pai era pedreiro e entregador e sua mãe dona de casa, cursou o ensino básico em sua cidade natal. Durante o seu ensino médio, estudou em uma cidade vizinha, Pau, onde foi destaque nos estudos e em esportes. Após a conclusão, mudou-se para Paris para cursar Filosofia na École Normale Superieure, uma das escolas de maior prestígio na França, concluindo sua graduação em 1954.

No ano seguinte, foi convidado a lecionar filosofia em uma cidade francesa, da região central, mas foi convocado pelo exército para servir em Versalhes. Porém, devido ao seu mal comportamento, foi punido e realocado para à guerra da Argélia que no período de 1930 a 1962 era colônia francesa, que buscava a pacificação por meio de lutas por libertação nacional.

Nesse período, foi professor-assistente na Universidade de Argel, entre os anos de 1958 e 1960, aproximou-se da antropologia quando passou a se interessar por aquela sociedade e, assim, estudá-la, focando, especialmente, a dualidade do capitalismo colonial e o desejo por independência. Por meio de fotos, registrava a vida dos camponeses e posteriormente escrevia sobre ela. Em 1960, precisou ir embora porque o grupo argelino havia tomado o poder e os franceses, dessa forma, estavam sendo ameaçados.

Em seu retorno a Paris, foi convidado por Raymond Aron para trabalhar na Universidade de Lille. Em Sorbornne, começou a preparar aulas e seminários e a ler cada vez mais autores como Durkheim, Marx e Weber. Durkhein lhe influenciou no método e no rigor, em questão de objetividade. Marx, posteriormente, lhe conduziu a estudar os conceitos do capital, classe e ideologia. Por fim, Weber lhe inspirou com os conceitos de 


\section{VOZES

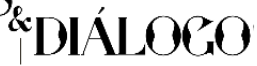

Itajaí, V. 20, n.01, jan-jun 2021

burocracia, a reprodução, a dominação e tipo ideal, criando assim uma teoria inédita e complexa.

Em 1962, fundou o Centre de Sociologie Européne, atualmente o Centre Européen Sociologie et Sciences Politiques. Tornou-se diretor de estudos da Escola de Estudos Superiores em Ciências Sociais. Nesse período, acontece sua aproximação e o início de inúmeras colaborações com Jean-Claude Passeron que posteriormente torna-se um de seus parceiros de escrita.

A partir das perspectivas abordadas por Bourdieu, tais quais a etnografia feita na Argélia, no Béarn e na própria sociedade francesa, por meio de discussões acerca de classe, economia, literatura, educação etc. A antropologia se estabeleceu na França e suas vastas pesquisas na área tiveram um grande impacto na sociologia francesa.

No ano de 1981, no qual a sua carreira caminhava para além da França, assumiu a cátedra de Sociologia no Collège de France. Sendo docente, também, em renomadas universidades ao redor do mundo. $\mathrm{O}$ autor teve como uma de suas marcas a defesa por uma interdisciplinaridade nas ciências humanas e ciências sociais, além de uma constante procura por independência intelectual. Estava sempre disposto a fortalecer escritores jovens e apoiar greves e trabalhadores, chegou a ser apelidado de "Sociólogo do povo". Faleceu em 23 de janeiro de 2002, em Paris, vítima de um câncer.

\section{Conceitos básicos}

Diante de sua produção intelectual, existem três conceitos que se destacam: campo, habitus e capital, que foram desenvolvidos nas décadas de 60 e 70 sobre a sociedade francesa, porém aplicáveis em inúmeras sociedades. Esses conceitos, como o próprio autor defendeu, são necessários para serem estudados em conjunto, em coexistência e interdependência.

Bourdieu (2006) parte da concepção de que a estrutura social é um sistema hierárquico transpassado por poderes, em que esses poderes determinam qual posição será ocupada por cada agente e lou grupo. O poder, assim, não é localizado ou estagnado, ele circula, existindo aqueles que o exercem ou não. A influência que um determinado grupo adquire sobre os demais é fruto de uma articulação entre poder financeiro, poder cultural, poder social e poder simbólico.

Para cada uma dessas articulações, Bourdieu (2006) denomina de capital, onde - a capitalização - terá uma posição de destaque em uma dada sociedade ou um contexto histórico. A distribuição desigual deles gera a desigualdade social. $\mathrm{O}$ autor divide os poderes em quatro tipos de capital: o capital econômico: abrange bens materiais, renda, posses; o capital cultural: seria o conhecimento adquirido formalmente, por meio de diplomas; o capital social: referente às relações sociais que geram algum tipo de capital, seria uma rede de relacionamentos que gerariam empregos, aumentos salarias, influência 


\section{VOZES \\ ¿DIÁLORO}

Itajaí, V. 20, n.01, jan-jun 2021

política; por fim, o capital simbólico: é o que confere honra e prestígio, status e tratamentos diferenciados e $\backslash$ ou privilégios sociais. A ausência ou soma desses poderes que são herdados ou adquiridos será determinante no lugar ocupado por grupos e agentes na hierarquia da sociedade.

Além de Capital, ele vai conceituar o que seria Campo - é constituído por meio de um sistema específico de relações objetivas, podendo ser de aliança ou de conflito, cooperação ou concorrência. Compreendido como "Um sistema no qual as instituições e os agentes, assim como seus atos e discursos, adquirem sentido apenas relacionalmente, através do jogo das oposições e das distinções” (BOURDIEU, 1999, p.133). Um campo é o local de disputas onde ocorrem as relações de poder.

Dessa forma, o habitus, então, seria um princípio estruturador de ações e comportamentos que influenciam diretamente na forma em que os agentes vão incorporar e reproduzir por meio da inculcação as ideologias, vivências, ideias e ideais partilhados naquele campo específico. Parte do princípio de que são estruturas estruturadas e estruturas estruturantes, ou seja, existe dentro do agente e fora dele. Pode também ser definido como um sistema de repertório que o agente adquire com as suas articulações por meio dos capitais.

Colocando em prática esses conceitos e mediante pesquisas sobre o consumo e as práticas de lazer da sociedade francesa, Bourdieu (2007), chegou à conclusão de que os gostos e os hábitos eram profundamente marcados pela trajetória dos agentes, pela forma que socializam com os outros e com a educação que recebem. Desta forma, o autor questiona se esse "gosto cultural” e os hábitos de vida não seriam o resultado das relações de força estabelecidas pelos capitais operando nas instituições.

No que se refere às ideias de dominação de uma classe sobre a outra, Bourdieu (2007) apresenta outro conceito importante, a violência simbólica, que se dá por meio de imposição de um dominador a um dominado. Ele define a violência simbólica como "Violência suave, insensível, invisível a suas próprias vítimas, que se exerce essencialmente pelas vias puramente simbólicas da comunicação e do conhecimento, ou, mais precisamente, do desconhecimento, do reconhecimento ou, em última instância, do sentimento" (BOURDIEU, 1999, p. 12).

\section{Bourdieu e gênero}

Bourdieu, tem sua primeira aproximação com os debates de gênero em 1960, por meio de um registro etnográfico em sua cidade natal (Denguin). Naquela época, ele começou a identificar os ritos de homens e mulheres da sua cidade para construírem relacionamentos. Eles estudavam em escolas separadas e o único momento que podiam se conhecer era quando os homens se sentavam nas praças e as mulheres passavam, muito comum nas cidades pequenas. Nesse período, houve a transformação do universo 


\section{VOZES $_{\text {\&IÁLORO }}^{\mid}$}

Itajaí, V. 20, n.01, jan-jun 2021

simbólico, ou seja, trânsitos simbólicos urbano-rurais, se consolidando pela acessibilidade da televisão.

Com a chegada da televisão, houve uma transformação na ideia de casamento e do que seria um "homem ideal”. As mulheres passam a enxergar outras possibilidades, buscando, assim, sair da cidade, alcançar empregos e constituir uma concepção diferente do que seria um marido e da própria beleza dos homens da sua cidade. Em contrapartida, os homens passam a ter vergonha de si. Por meio dessa pesquisa, Bourdieu (2006) escreve o livro "O baile dos solteiros", ainda não traduzido para o português, mas adaptado para um texto chamado "O camponês e seu corpo".

Em 1998, vai publicar uma das suas obras mais conhecidas, "A Dominação Masculina”, com grande relevância teórica do debate feminista, via filosofia, teoria de gênero e psicanálise. Parte de um registro etnográfico durante o período em que estava na Guerra da Argélia, sobre a Cabília e a Culture berbere, escrito como um diálogo direto com a teoria de gênero e reinvindicações do movimento feminista.

Bourdieu (1999), vai compreender a dominação masculina como sendo validada por meio da violência simbólica:

Incorporamos, sob a forma de esquemas inconscientes de percepção e de apreciação, as estruturas históricas da ordem masculina; arriscamo-nos, pois, a recorrer, para pensar a dominação masculina, a modos de pensamento que são eles próprios produto da dominação (BORDIEU, 1999, p. 17)

A dominação masculina se projeta por meio do habitus, nesse sentido, o agente praticaria uma violência simbólica, iria impor uma ideologia, ideia ou ideal para essa minoria ou, como coloca o autor, os dominados, no caso de gênero seria a naturalização dessa dominação. O homem por meio do machismo, patriarcado e do sexismo, seria o dominador, além das próprias mulheres que se encontrariam tão imersas nesse habitus que agiriam de forma preconceituosa. Ele vai ressaltar que acabar com a dominação masculina não é algo fácil, mas se dará por todo um processo em que os agentes tomariam consciência que são reprodutores desses preconceitos e tentariam, de alguma forma, cada vez mais minimizá-los.

\section{Considerações}

Os conceitos de Pierre Bourdieu para os estudos sociais são de extrema importância. Como já foi citado, as teorias bourdiesianas são utilizadas em várias áreas como: educação, comunicação, economia, artes, literatura etc. $\mathrm{O}$ próprio Bourdieu buscava abranger esses campos e trazê-los também para seus estudos. Essas várias vozes podem ser vistas em suas obras, em que ele conversa com autores de várias correntes e concepções, muitas vezes distintas, mas que enriquecem o seu debate acerca do social. 


\section{VOZES $_{\text {\&DÁLOGO }}^{\mid}$}

Itajaí, V. 20, n.01, jan-jun 2027

São inúmeras as contribuições de Bourdieu para os estudos sociais, destacando-se os estudos sobre os materiais simbólicos e como eles são condicionados nas vidas dos agentes, além das relações de poder que são estabelecidas por capitais. Um crítico dos mecanismos de reprodução das desigualdades sociais, se destacou por abordar as questões de habitus, campo, capital, poder simbólico, violência simbólica, entre outros. Seus conceitos são abordados para além da Europa, além de serem contemporâneos, podendo assim abarcar as desigualdades sociais sofridas em diferentes sociedades e culturas.

\section{Referências}

BOURDIEU, P. A distinção: crítica social do julgamento. São Paulo: Edusp; Porto Alegre, RS: Zouk, 2007.

BOURDIEU, P. A Dominação Masculina. Guarulhos - SP: Bertrand, 1999.

BOURDIEU, P. O Poder Simbólico. Guarulhos - SP: Bertrand, 2006.

REZENDE, M.O. "Pierre Bourdieu"; Brasil Escola. Disponível em: https://brasilescola.uol.com.br/sociologia/pierre-bourdieu.htm. Acesso em 16 de novembro de 2020. 